Supplement of Atmos. Chem. Phys., 15, 7685-7702, 2015

http://www.atmos-chem-phys.net/15/7685/2015/

doi:10.5194/acp-15-7685-2015-supplement

(C) Author(s) 2015. CC Attribution 3.0 License.

(c) (i)

Atmospheric

Chemistry

and Physics

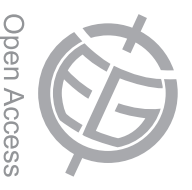

Supplement of

\title{
Estimates of black carbon emissions in the western United States using the GEOS-Chem adjoint model
}

\author{
Y. H. Mao et al. \\ Correspondence to: Q. B. Li (qli@atmos.ucla.edu)
}

The copyright of individual parts of the supplement might differ from the CC-BY 3.0 licence. 
Fig. S1. Sensitivities of surface BC mass to the scaling factors of BC emissions as computed using GEOS-Chem adjoint and the finite difference approximation (Eq. 1, unit: $\mathrm{kg} /$ grid box). Results are from 1-week simulations for biomass burning (top panel) and anthropogenic emissions (bottom panel) for August 2006. Solid lines are regression lines.

Fig. S2. (top) Normalized a posteriori cost function $J\left(\boldsymbol{X}_{n}\right) / J\left(\boldsymbol{X}_{0}\right)$ as a function of the regularization parameter $\gamma_{r}$ (Eq. 3) for August 2006. (bottom) Reduction in the normalized cost function $J\left(\boldsymbol{X}_{i}\right) / J\left(\boldsymbol{X}_{0}\right)$ at $2^{\circ} \times 2.5^{\circ}$ and $0.5^{\circ} \times 0.667^{\circ}$ for August 2006. 

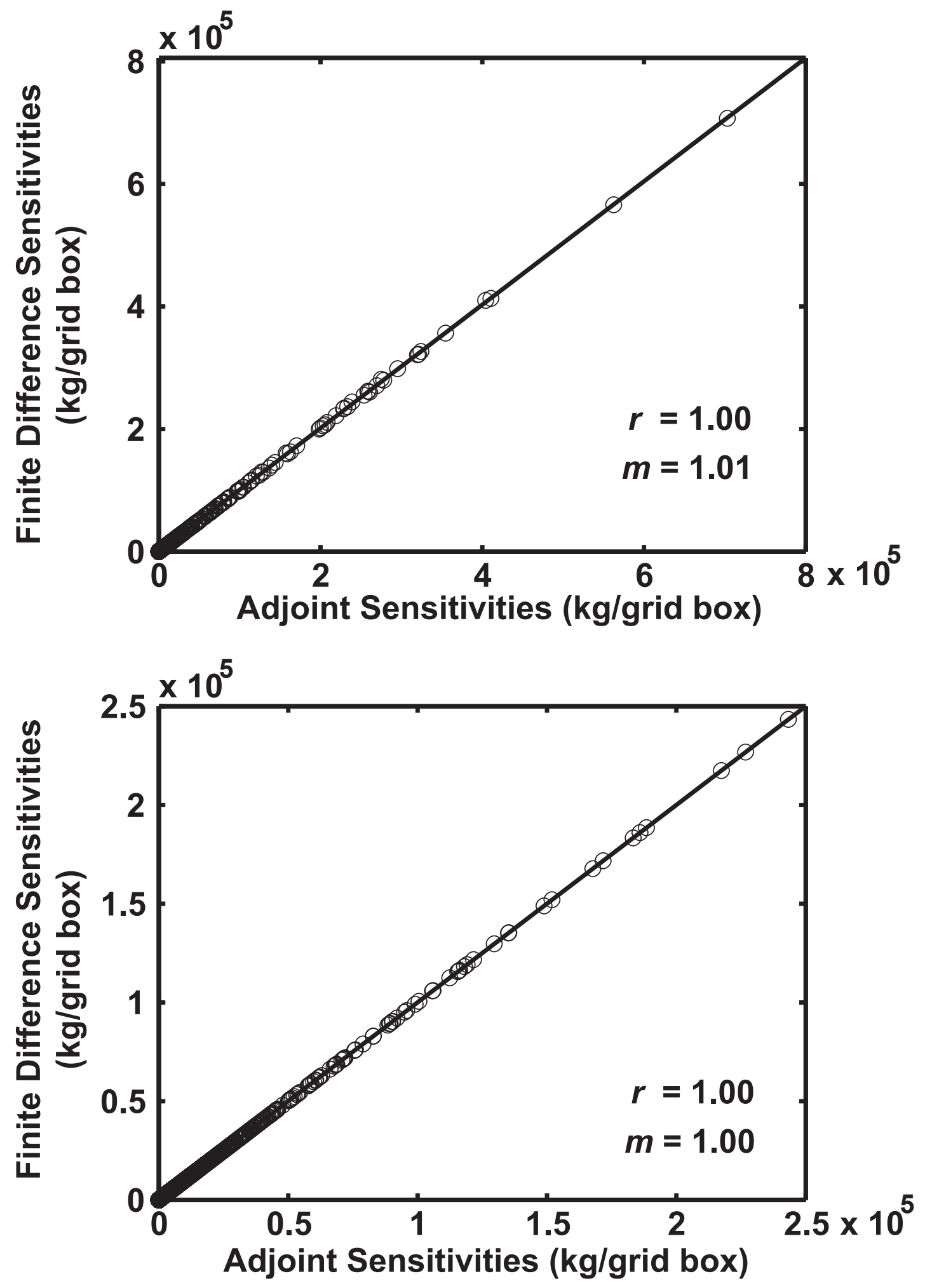

Fig. S1 

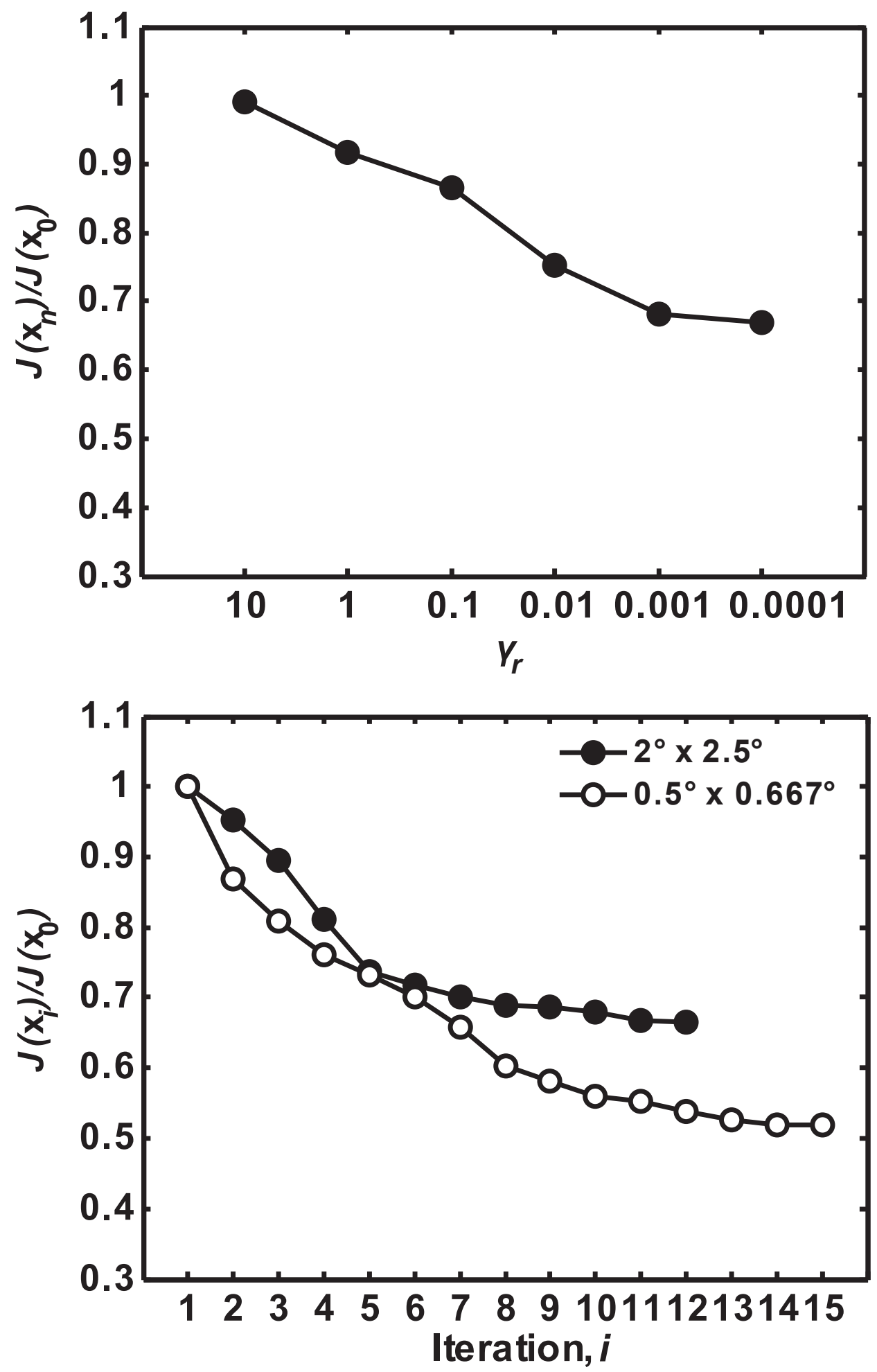

Fig. S2 